\title{
Malondialdehyde, Glutathione Peroxidase, and Superoxide Dismutase in Cerebrospinal Fluid During Cerebral Vasospasm in Monkeys
}

\author{
R. Loch Macdonald, Bryce K.A. Weir, Tim D. Runzer and Michael G.A. Grace
}

\begin{abstract}
Cerebral vasospasm may result from lipid peroxidation induced by oxyhemoglobin in the subarachnoid space after subarachnoid hemorrhage. To test this theory, vasospasm was induced in monkeys by intrathecal injections of oxyhemoglobin or supernatant fluid from autologous blood incubated in vitro. Concentration of malondialdehyde (MDA), a product of lipid peroxidation, was elevated in cerebrospinal fluid (CSF) in association with vasospasm caused by oxyhemoglobin and supernatant fluid. Intrathecal injections of methemoglobin or bilirubin did not cause vasospasm or increased CSF MDA. Activity of glutathione peroxidase in CSF increased significantly after injection of oxyhemoglobin and methemoglobin. There were no significant changes in CSF superoxide dismutase activity although there was a trend towards higher activities in animals treated with oxyhemoglobin, methemoglobin, bilirubin, and supernatant fluid. These results show oxyhemoglobin-induced vasospasm is associated with MDA and lipid peroxidation in the subarachnoid space. Furthermore, detection of peroxidation products after injection of oxyhemoglobin in the absence of erythrocyte membranes indicates that oxyhemoglobin may directly damage cerebral arteries and brain by inducing lipid peroxidation in these structures. Depletion of free-radical scavenging enzymes in CSF did not seem necessary for development of vasospasm. In fact, there was a tendency for vasospasm to elevate enzyme activities, as if production of scavengers was induced by excess free radicals in the subarachnoid space.
\end{abstract}

\begin{abstract}
RÉSUMÉ: Malondialdéhyde, glutathion peroxydase et superoxyde dismutase dans le liquide céphalo-rachidien pendant le vasospasme cérébral chez le singe. Le vasospasme cérébral peut résulter de la peroxydation lipidique induite par la présence d'oxyhémoglobine dans l'espace sous-arachnoïdien, à la suite d'une hémorragie sous-arachnoïdienne. Pour vérifier cette hypothèse, un vasospasme a été induite chez des singes par injection intrathécale d'oxyhémoglobine ou de liquide surnageant de sang autologue incubé in vitro. La concentration de malondialdéhyde (MDA), un produit de la peroxydation lipidique, était élevée dans le liquide céphalo-rachidien (LCR) en association avec le vasospasme causé par l'oxyhémoglobine et le liquide surnageant. L'injection intrathécale de méthémoglobine ou de bilirubine n'a pas causé de vasospasme ou augmenté la MDA.du LCR. L'activité de la glutathione peroxydase dans le LCR a augmenté significativement après injection d'oxyhémoglobine ou de méthémoglobine. Il n'y a pas en de changement significatif dans l'activité de la superoxyde dismutase du LCR, bien qu'il y ait eu une tendance vers des activités plus grandes chez les animaux traités avec l'oxyhémoglobine, la méthémoglobine, la bilirubine et le liquide sugnageant. Ces résultats montrent que le vasospasme induit par l'oxyhémoglobine est associé à la MDA et à la peroxydation lipidique dans l'espace sous-arachnoïdien. De plus, la détection des produits de la peroxydation après injection d'oxyhémoglobine, en l'absence de membranes érythrocytaires, indique que l'oxyhémoglobine peut endommager directement les artères cérébrales et le cerveau en induisant une peroxydation lipidique dans ces structures. Une déplétion des enzymes épurant les radicaux libres dans le LCR n'a pas semblé nécessaire au développement du vasospasme. En fait, le vasospasme avait tendance à élever l'activité des enzymes, comme si la production de ces enzymes était induite par l'excès de radicaux libres dans l'espace sous-arachnoïdien.
\end{abstract}

Can. J. Neurol. Sci. 1992; 19: 326-332

There is evidence that oxyhemoglobin $(\mathrm{OxyHb})$ released from hemolyzing subarachnoid erythrocytes causes cerebral vasospasm following aneurysmal subarachnoid hemorrhage (SAH).'.2 How OxyHb causes vasospasm, however, is unclear. One theory suggests $\mathrm{OxyHb}$ initiates free radical reactions in subarachnoid clot after SAH, resulting in production of toxic lipid peroxides. ${ }^{1.3}$ These lipid peroxides, which permeate the cerebrospinal fluid (CSF), enter the cerebral arteries and cause arterial narrowing. Lipid peroxides in CSF could arise from breakdown of red blood cell membranes, from reaction with

From the Division of Neurosurgery (R.L.M., B.K.A.W., T.D.R.), Department of Surgery (M.G.A.G.), University of Alberta, Edmonton Received August 6, 1991. Accepted in final form March 13, 1992.

Reprint requests to: B.K.A. Weir, M.D., Department of Surgery, 2D.102 Walter MacKenzie Health Sciences Center, University of Alberta, Edmonton, Alberta, Canada T6G IV6 
lipids in brain or arterial wall, or from both. Vasospasm and peroxidation occurring in an experimental system where vasospasm is caused by $\mathrm{OxyHb}$ in the absence of erythrocyte membranes would suggest there is lipid peroxidation of arterial walls. This would favor direct free radical-mediated action of $\mathrm{OxyHb}$ on arteries as a cause of vasospasm, as opposed to a secondary effect of $\mathrm{OxyHb}$ via generation of lipid peroxides from red cells. The pathogenesis of smooth muscle contraction and of vasospasm by these two pathways would differ. ${ }^{4}$

To see if vasospasm induced by OxyHb alone is associated with lipid peroxidation, monkeys were given intrathecal injections of $\mathrm{OxyHb}$, methemoglobin (MetHb), and bilirubin. Vasospasm was assessed by angiography and malondialdehyde (MDA), a product of lipid peroxidation, was measured in CSF. Levels of free-radical scavenging enzymes were also measured to determine if their depletion was necessary for development of vasospasm. Results of angiography and pathologic examination of cerebral arteries are contained in a separate report. ${ }^{5}$

\section{Materials AND Methods}

\section{Protocol}

Forty female cynomolgus monkeys (Macaca fascicularis) were assigned by restricted randomization to one of 5 groups of 8 . On day 0 , each animal underwent baseline physical assessment and cerebral angiography. A right pterional craniectomy was made and the basal cisterns were opened. An Ommaya reservoir was situated in the subcutaneous tissue and connected to a catheter along the right middle cerebral artery (MCA). On days 1 to 6 , animals received intrathecal injections, twice a day, of one of the following solutions: 1) OxyHb, 2) MetHb, 3) bilirubin, 4) mock $\mathrm{CSF}^{6}$, and 5) supernatant fluid from an incubated autologous blood-mock CSF mixture. Prior to each injection, CSF was withdrawn from the Ommaya reservoir and stored at $-60^{\circ} \mathrm{C}$. The CSF from days 2,4 , and 6 was analyzed for concentration of MDA and activity of superoxide dismutase (SOD) and glutathione (GSH) peroxidase. Three additional mixtures of blood and mock CSF were prepared and supernatant fluid from these was assayed each day for MDA and for activity of GSH peroxidase and SOD. On day 7, angiography was repeated and animals were killed. Content of MDA and activities of SOD and GSH peroxidase were measured in 3 samples of each of the injected solutions $(\mathrm{OxyHb}$, MetHb, mock CSF, and bilirubin).

Protocols were reviewed by the Animal Ethics Review Committee of University of Alberta. Care and surgery of animals were according to standards set by the Canadian Council on Animal Care.

\section{Solution Preparation}

Oxyhemoglobin was prepared from pure human hemoglobin (Sigma Chemical Co., St. Louis, Missouri) by reduction with a 10 -fold molar excess of sodium dithionite and dialysis for 24 hours in 400 volumes mock CSF (Elliott's solution B). ${ }^{6.7}$ Methemoglobin was prepared by oxidation of pure human hemoglobin with a 1.2-fold molar excess of potassium ferricyanide followed by dialysis. Spectrophotometry using a cooximeter (Instrumentation Laboratories model 282, Lexington,
Massachusetts) showed the OxyHb solution contained 50\% $\mathrm{OxyHb}$ (the maximum amount which could be achieved) and $50 \% \mathrm{MetHb}$. The MetHb solution contained over $99 \%$ MetHb.

Purified bilirubin (Sigma Chemical Co., St. Louis, Missouri) was suspended in mock CSF immediately prior to injection. Each injection contained $2.1 \mathrm{mg}$ bilirubin. Animals destined for injections of supernatant fluid had equal volumes of autologous heparinized blood and mock CSF mixed in a sterile container on day 0 . The solution was incubated at $37^{\circ} \mathrm{C}$, gently agitated, and kept in the dark. For injection, a small amount was removed, centrifuged ( $100 \mathrm{G}$ for 10 minutes), and the supernatant fluid removed for injection. The remaining solution was replaced in the sterile container along with additional mock CSF to maintain constant volume.

Injected solutions were checked periodically for sterility. Osmolarity and $\mathrm{pH}$ of hemoglobin and bilirubin solutions were $275 \mathrm{mOsm} / \mathrm{L}$ and 7.4, respectively. Hemoglobin content of supernatant fluid has been reported. ${ }^{5}$ Supernatant fluid osmolarity ranged from 273 to $293 \mathrm{mOsm} / \mathrm{L}$ and $\mathrm{pH}$ varied from 7.4 to 8.1 .

\section{Dose Calculations}

Experiments using cynomologus monkeys at the University of Alberta have shown that $5 \mathrm{ml}$ of clotted blood causes vasospasm when placed in the subarachnoid space. This clot contains $600 \mathrm{mg}$ hemoglobin. Monkeys injected with OxyHb, $\mathrm{MetHb}$, and supernatant fluid received the same total dose of hemoglobin $(600 \mathrm{mg})$ injected over the course of 12 injections. Total dose of bilirubin injected $(25 \mathrm{mg}$ ) was that which would be produced by complete metabolism of $600 \mathrm{mg}$ of hemoglobin. Animals in the mock CSF group received 12 injections of $1 \mathrm{ml}$ of Elliott's solution B.

\section{Day 0: Baseline Assessment, Cerebral Angiography, Craniectomy}

Monkeys were sedated with ketamine hydrochloride, 6 to 10 $\mathrm{mg} / \mathrm{kg}$, weighed, and examined. They were intubated endotracheally and ventilated on a 2:1 mixture of $\mathrm{N}_{2} \mathrm{O}: \mathrm{O}_{2}$ via a variable-phase animal respirator (Harvard Apparatus, Inc., Millis, Massachusetts). End-tidal $\mathrm{PCO}_{2}$ was monitored and adjusted to approximately $40 \mathrm{~mm} \mathrm{Hg}$ (Patient monitor 78356A, Hewlett Packard, Federal Republic of Germany). Paralysis (gallamine, 2 $\mathrm{mg} / \mathrm{kg}$ intravenous) and anaesthesia (fentanyl, $5 \mu \mathrm{g} / \mathrm{kg}$ intravenous) were induced. A heating pad was used to keep body temperature at $37^{\circ} \mathrm{C}$ as monitored by a rectal thermometer (Telethermometer, Yellow Springs Instrument Co., Yellow Springs, Ohio). Penicillin G, 100,000 IU/kg and atropine 0.6 $\mathrm{mg} / \mathrm{kg}$, were administered intravenously.

Using magnification and sterile technique, the femoral artery on either side was dissected and catheterized with a sigmoid-tip, radiopaque, 5-F polyethylene catheter. Under fluoroscopy, the catheter was advanced into the communis artery and connected via a 3-way stopcock to a pressure transducer for measurement of blood pressure and heart rate (Statham P23dB pressure transducer, Statham Instrument Co., Oxnard, California). Blood pressure and heart rate were continuously recorded on a Beckman Dynograph R611 eight-channel recorder (Beckman Instruments, Inc., Fullerton, California). A single anteroposterior, arterialphase cerebral angiogram was obtained by injecting $12 \mathrm{ml}$ of iothalamate meglumine at $200 \mathrm{psi}$ via a Cordis injector (Cordis 
Corp., Miami, Florida). Exposure factors were uniform and a magnification control standard was included in each radiograph.

Anaesthesia was supplemented with sodium pentobarbital, $25 \mathrm{mg} / \mathrm{kg}$ intravenously. Ten $\mathrm{ml}$ of $20 \%$ mannitol was administered intravenously and ventilation was adjusted to lower endtidal $\mathrm{PCO}_{2}$ to $30 \mathrm{~mm} \mathrm{Hg}$. The head was turned left and fixed in three-point pin fixation. A right frontotemporal craniectomy was made, centered on the pterion. Dura mater was opened and the frontal lobe elevated and the temporal lobe depressed, exposing the ipsilateral optic nerve and internal carotid artery $\left(\mathrm{C}_{4}\right)$. Under the operating microscope, arachnoid membrane over the precommunicating segment of the anterior cerebral artery, the sphenoidal segment of the $\mathrm{MCA}$, and $\mathrm{C}_{4}$ was divided, exposing underlying arteries. Dura mater was closed with a patch of deep temporalis fascia sutured in place with 6-0 silk suture. A CSF reservoir (Ommaya CSF reservoir, American V. Mueller, Chicago, Illinois) was placed in the subcutaneous space and connected to a short length of silicone catheter (Pundez ventricular catheter, American V. Mueller, Chicago, Illinois) which was threaded through the dura to lie along the sylvian fissure. Temporalis muscle, superficial fascia, and skin were closed in layers with 3-0 silk suture and 3-0 monofilament polyethylene suture. Paralysis was then reversed with prostigmine $(0.07$ $\mathrm{mg} / \mathrm{kg})$ and atropine $(0.02 \mathrm{mg} / \mathrm{kg})$ intravenously and animals were ventilated with $100 \% \mathrm{O}_{2}$ until they were breathing spontaneously. They were extubated when their gag reflex returned.

\section{Days 1 to 6: Intrathecal Injections, Clinical Observation}

Intrathecal injections, twice a day for 6 days, commenced the day following craniectomy. Monkeys were sedated with ketamine, 6 to $10 \mathrm{mg} / \mathrm{kg}$ intramuscular, and the appropriate solution injected into the Ommaya reservoir. Cerebrospinal fluid was aspirated from the reservoir prior to injection and stored at $-60^{\circ} \mathrm{C}$ for analysis.

\section{Day 7: Cerebral Angiography, Killing}

On day 7 , angiography was repeated under identical conditions to day 0 angiography. Animals were killed by intravenous injection of pentobarbital $(50 \mathrm{mg} / \mathrm{kg}$ ) and exsanguination.

\section{Biochemical Measurements}

Malondialdehyde was measured by high pressure liquid chromatography (HPLC). ${ }^{8}$ A Waters series $3 \mathrm{~B}$ liquid chromatograph and Waters spectrophotometer set at $267 \mathrm{~nm}$ were used. The HPLC separations were performed on a Whatman chromasorb CIB 5 micron ODS column $(4.6 \times 150 \mathrm{~mm})$ with a mobile phase of $14 \%(\mathrm{v} / \mathrm{v})$ acetonitrile in $50 \mathrm{mM}$ myristyltrimethylammonium bromide and $1 \mathrm{mM}$ sodium phosphate $(\mathrm{pH}$ 6.4) run at $1.0 \mathrm{ml} / \mathrm{min}$ at room temperature. Superoxide dismutase activity was measured by direct assay with potassium superoxide as described by Marklund. ${ }^{9}$ One unit of activity was defined as the activity that disproportionates superoxide anion radical at a rate of 0.1 per second. Activity of GSH peroxidase was measured by peroxidation of cumene hydroperoxide as described by Wendel. ${ }^{10}$ For samples containing hemoglobin, correction for pseudoperoxidase activity of hemoproteins was made. " A unit of GSH peroxidase activity was defined as that required to consume $90 \%$ of GSH in the assay mixture within 1 minute.

\section{Data Analysis}

Diameter of the following cerebral arteries were measured at predetermined points 6 times with a calibrated optical microme- ter and a mean value calculated: extradural internal carotid artery $\left(\mathrm{C}_{3}\right), \mathrm{C}_{4}, \mathrm{MCA}$, and anterior cerebral artery (ACA). Data were coded, entered into a computer, and edited. Mean MDA concentration was calculated for each group by combining data from each time period and comparing means using the KruskalWallis test. Activities of GSH peroxidase and SOD were compared between groups for each time period by analysis of variance followed by Scheffe's multiple comparison procedure. The level of significance for all comparison tests was $p<0.05$.

\section{RESULTS}

\section{Clinical Status, Cerebral Vasospasm}

Results of clinical status and degree of vasospasm have been published ${ }^{5}$ and may be summarized as follows. Five animals in each of the groups injected with supernatant fluid and $\mathrm{OxyHb}$ developed signs of meningeal irritation, lethargy, and anorexia. Three animals in the MetHb group and one monkey injected with bilirubin developed similar signs. In the OxyHb group, between day 0 and 7 , there was significant decrease in diameter of right $\mathrm{C}_{3}(19 \% \pm 5 \%, \mathrm{p}<0.05), \mathrm{C}_{4}(18 \% \pm 11 \%, \mathrm{p}<0.005)$, ACA $(20 \% \pm 13 \%, p<0.05)$, and MCA $(27 \% \pm 11 \%, p<$ $0.005)$. After injection of supernatant fluid, significant reduction in right $\mathrm{C}_{3}(22 \% \pm 5 \%, \mathrm{p}<0.05), \mathrm{C}_{4}(17 \% \pm 13 \%, \mathrm{p}<0.05)$, $\operatorname{ACA}(31 \% \pm 22 \%, p<0.05)$, and MCA $(26 \% \pm 16 \%, p<0.05)$ diameters were noted. No significant changes in vessel diameter developed after injection of bilirubin, MetHb, or mock CSF.

\section{Malondialdehyde}

Average concentration of MDA in CSF was calculated by combining data ( 8 measurements per day per group) from days 2,4 , and 6 (Figure 1). Although there were no significant differences between groups, higher amounts of MDA were present in CSF of animals injected with $\mathrm{OxyHb}$ (mean in $\mathrm{nmol} / \mathrm{ml} \pm$ standard deviation, $0.45 \pm 1.28$ ) and supernatant fluid $(0.47 \pm 0.89)$ as compared to those injected with MetHb $(0.16 \pm 0.35)$, bilirubin $(0.22 \pm 0.65)$, and mock CSF $(0.03 \pm 0.09)$.

\section{Superoxide Dismutase, Glutathione Peroxidase}

Results of CSF activities of SOD and GSH peroxidase and numbers of samples analyzed at each time period are shown in Figures 2 and 3. For SOD activity, no significant differences were noted between groups at any time although there was consistently higher activity in animals injected with $\mathrm{OxyHb}$ and MetHb. Supernatant fluid-injected animals had elevated activity of SOD on day 6, by which time large amounts of OxyHb were present in the injected solution. Glutathione peroxidase activity increased significantly $(p<0.05)$ in CSF on day 2 in animals treated with $\mathrm{OxyHb}$ and $\mathrm{MetHb}$ and on day 6 in the $\mathrm{OxyHb}$ group $(p<0.05)$, although this latter result was based on a single value.

\section{Supernatant Fluid, Injected Solutions}

Concentration of MDA increased until day 6 and then slowly fell to baseline by day 10 (Figure 4). Maximum levels detected were of similar magnitude to average amounts found in CSF of animals injected with supernatant fluid (Figure 1). No MDA was detected in any of the samples of $\mathrm{OxyHb}$, MetHb, bilirubin, or mock CSF solutions.

Activity of SOD in supernatant fluid increased each day (Figure 4). Glutathione peroxidase was detected on the first 3 


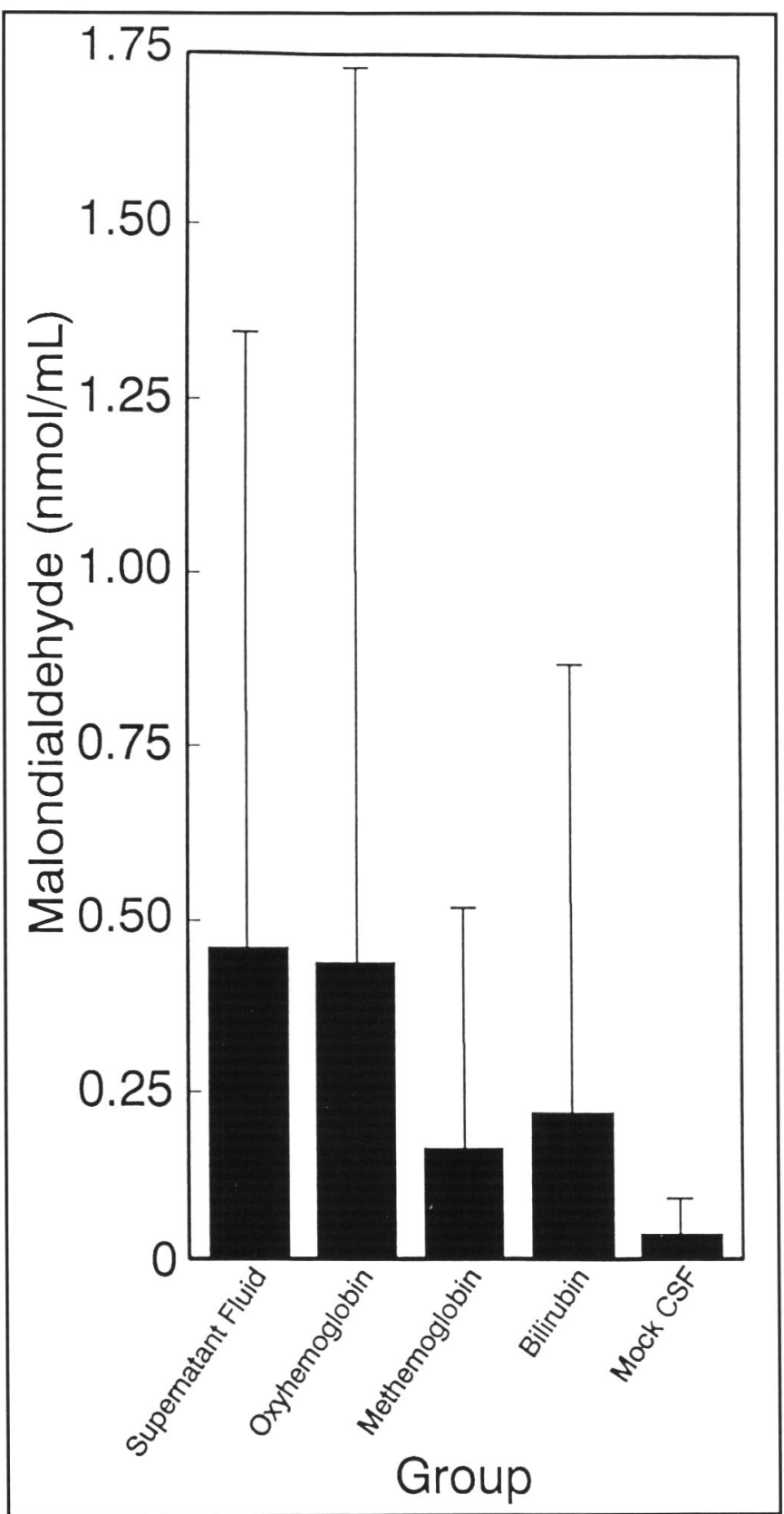

Figure $1-B a r$ graph of concentration of malondialdehyde (mean \pm standard deviation) in aspirated cerebospinal fluid from each group. 24 samples were analyzed in each group. There were no significant differences between groups.

days of incubation after which activity was minimal or absent (Figure 4). Glutathione peroxidase and SOD activities were not present in injected solutions of $\mathrm{OxyHb}, \mathrm{MetHb}$, bilirubin, or mock CSF.

\section{Discussion}

These results show that $\mathrm{OxyHb}$-induced vasospasm is associated with lipid peroxidation in the subarachnoid space. Vasospasm induced by $\mathrm{OxyHb}$ is morphologically and angiographically similar to that produced by whole blood clot. ${ }^{5}$ This suggests that erythrocyte membranes, while constituting a

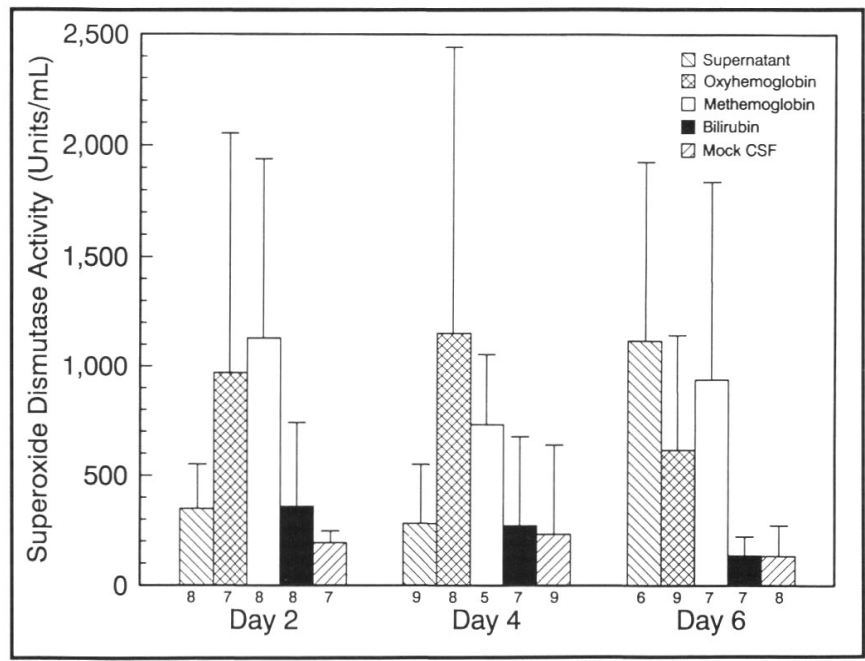

Figure 2 - Bar graph of activity of superoxide dismutase (mean \pm standard deviation) in cerbrospinal fluid aspirated from each group for days 2, 4, and 6. Number of samples analyzed is shown below each bar: There were no significant differences between groups at any time period.

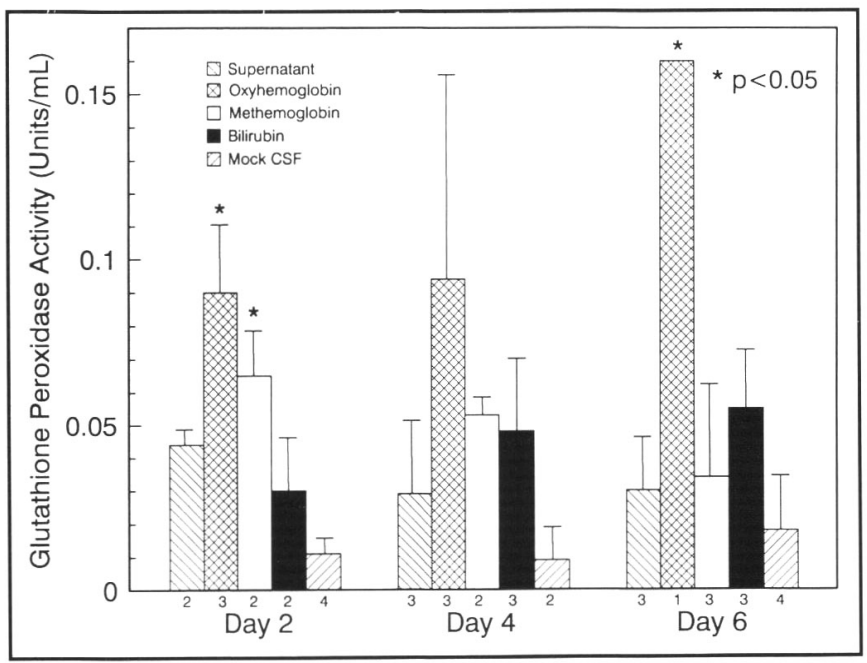

Figure $3-$ Bar graph of activity of glutathione peroxidase (mean \pm standard deviation) in cerebrospinal fluid aspirated from each group for days 2, 4, and 6. Number of samples analyzed is shown below each bar. Activity was significantly elevated in the $\mathrm{OxyHb}$ and MetHb groups on day 2 and in the OxyHb group on day 6.

potential source of injurious lipid peroxides, are not necessary for vasospasm to develop. Thus, if lipid peroxidation is important in vasospasm, then it is likely that the key free radical reactions are induced by $\mathrm{OxyHb}$ in arterial walls. In support of this, hemoglobin has been shown to enter arterial walls after SAH. ${ }^{12}$ We cannot, however, exclude the possibility that these reactions also occur in brain tissue, although the infrequent development of neurologic deficits in the animals suggests that reactions were of minor importance. It remains difficult, however, to conclude that free-radical mechanisms mediate the vasospastic activity of $\mathrm{OxyHb}$. Proof of this would require evidence that lipid peroxidation precedes development of OxyHb-induced vasospasm ${ }^{13,14}$ 
since vessel wall damage which accompanies such vasospasm would be expected to produce lipid peroxides, as most damaged
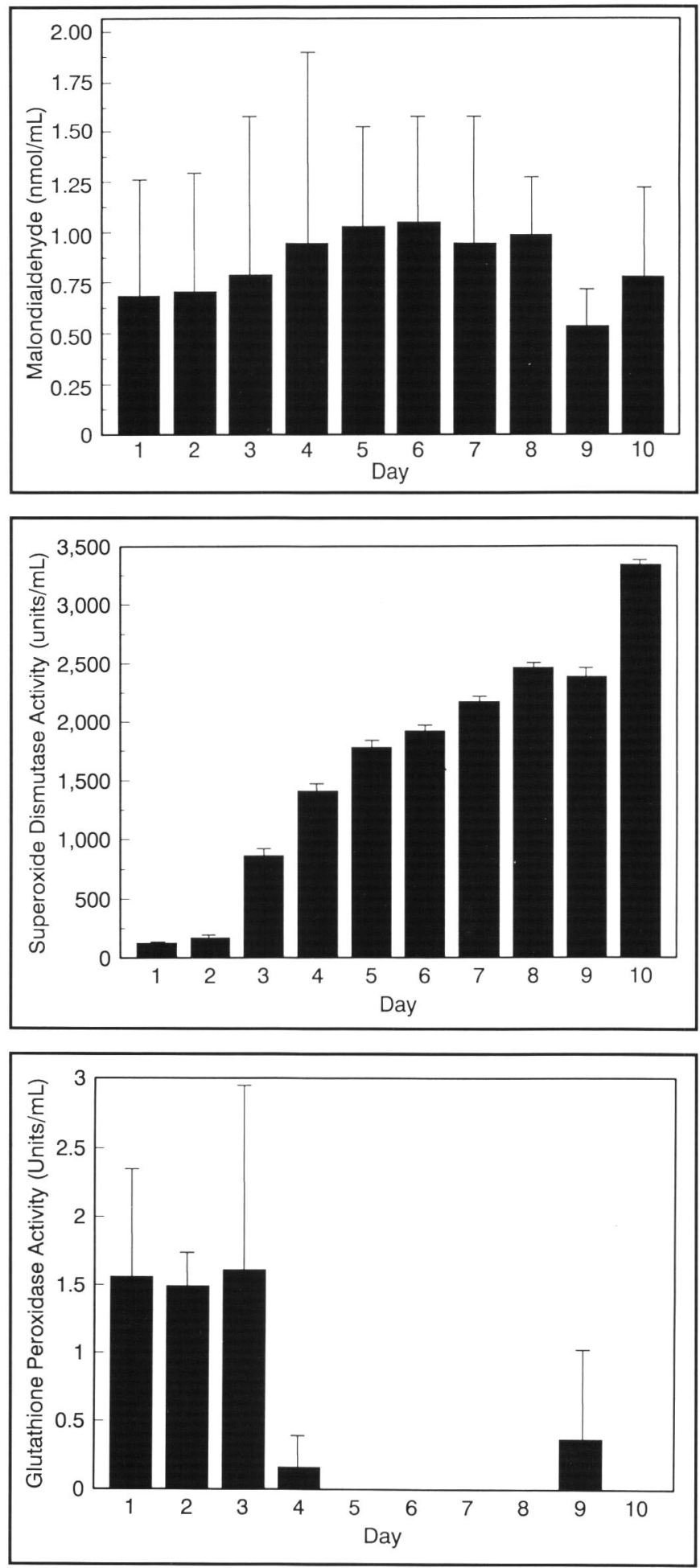

Figure $4-$ Changes in malondialdehyde concentration ( $\mathrm{nmol} / \mathrm{ml})$ (top) and activities of superoxide dismutase (middle) and glutathione peroxidase (bottom, both in Units $/ \mathrm{ml}$ ) in supernaiant fluid from a mixture of blood and mock CSF incubated in vitro, by day (all values are mean \pm standard deviation). tissues do. ${ }^{15}$ Second, inhibition of lipid peroxidation should alleviate vasospasm. Although U74006F, an inhibitor of iron-dependent lipid peroxidation, significantly diminished vasospasm in a primate model, substantial arterial narrowing persisted even after treatment with $\mathrm{U} 74006 \mathrm{~F} .{ }^{16,17}$ That $\mathrm{OxyHb}$ can contract and subsequently damage cerebrovascular smooth muscle by free radical-mediated mechanisms is, however, consistent with experiments in vitro. ${ }^{2.13 .18}$

Asano et al. ${ }^{1}$ first proposed free radical reactions might be important in generating vasospasm when they noted that $\mathrm{OxyHb}$ autooxidizes, releasing superoxide anion radical ${ }^{19,20}$ which could be converted to hydroxyl radical by the iron-catalyzed HaberWeiss reaction. Hydroxyl radical could initiate and propagate lipid peroxidation reactions, end-products of which include MDA. ${ }^{21}$ Vasospasm was postulated to result from vasoconstriction precipitated by toxic lipid peroxides or possibly by lipoperoxide-induced stimulation of lipoxygenase activity and inhibition of prostacyclin synthetase activity in the arterial wall. ${ }^{1.3}$ Direct action of OxyHb on the arterial wall was not ruled out. Indeed, lipid peroxides are vasoconstrictors ${ }^{3,4.22 .23}$ and they are present in CSF after SAH. ${ }^{24}$ High concentrations are associated with vasospasm ${ }^{3,25,26}$ and lipid peroxides have been found within dog arterial walls made vasospastic by whole blood ${ }^{27}$ although induction of lipid peroxidation in the subarachnoid space in vivo by $\mathrm{OxyHb}$ alone has rarely been reported. ${ }^{28}$ The ability of U74006F to significantly reduce vasospasm following SAH in primates ${ }^{16,17}$ further suggests lipid peroxidation contributes to vasospasm.

Although lipid peroxides may be important in vasospasm and their production is likely through reactions catalyzed by $\mathrm{OxyHb}$ or by iron released from it, ${ }^{15}$ the present findings indicate that $\mathrm{OxyHb}$ or its iron molecules can induce peroxidation in other structures, such as arterial wall. Peroxidation of the arterial wall may decrease membrane fluidity, increase membrane leakiness, and damage membrane proteins, including ion channels. ${ }^{2.15 .25}$ Direct arterial wall free radical-induced lipid peroxidation and damage due to lipid peroxides produced by erythrocyte membranes may both be components of the pathogenesis of vasospasm. Production of eicosanoids, which is by enzymatically-controlled lipid peroxidation ${ }^{29}$ also increases in arterial walls exposed to OxyHb. ${ }^{30.31}$

Lipid peroxidation is normally prevented in aerobic organisms by enzymes including SOD, GSH peroxidase, and catalase as well as by antioxidant chemicals. Cerebrospinal fluid contains low levels of free radical scavenging enzymes. ${ }^{32}$ Inadequate ability of CSF to quench free radicals after SAH has been suggested to be prerequisite for development of lipid peroxidation and vasospasm. Activities of these enzymes have been measured in CSF after SAH with conflicting results. Our results for SOD activity differ from previous reports which show vasospasm is associated with diminished CSF SOD activity as compared to activity in SAH patients without vasospasm..$^{25.27}$ We did not introduce whole blood into the subarachnoid space and influx of SOD from blood which initially elevates SOD activity after SAH was not present. Increased enzyme activity in response to oxidative stress, presumably through induction of enzyme synthesis, has been described in other systems. ${ }^{32}$

Investigations have shown GSH peroxidase activity increases in CSF after SAH, findings which concur with our results. 25.27 The reason for increased GSH peroxidase activity is unclear 
although excess hydrogen peroxide, a substrate for GSH peroxidase, could be produced by SOD and by free radical reactions in $\mathrm{CSF}$ after SAH and this could induce enzyme synthesis. ${ }^{32}$ Decreased SOD activity after SAH has been cited as evidence that free radical scavenging ability of CSF is depleted after $\mathrm{SAH}^{25,27}$ a theory at odds with findings related to GSH peroxidase activity.

Levels of free radical scavenging enzymes we detected were apparently not enough to prevent lipid peroxidation from occurring. There are several possible reasons for this. Activities of SOD and GSH peroxidase which we measured were, despite some trend towards elevations in some groups, low when compared to activities which seem to be required for protection from free radical damage in vivo in other experimental systems. Little data exist regarding what the optimum levels of free radical scavenging enzymes are in vivo. ${ }^{32}$ Furthermore, despite increased CSF levels, enzymes may be depleted where free radicals are generated. Hemoglobin penetrates the arterial wall adventitia after SAH, possibly clogging CSF-filled nutrient pores and excluding these enzymes. ${ }^{12}$ Sakaki et al. found dog arterial walls had diminished GSH peroxidase activity during vasospasm while CSF activity of GSH peroxidase was significantly elevated ${ }^{27}$ Superoxide dismutase activity was preserved in the arterial wall but depleted in CSF. Even if SOD and GSH peroxidase entered arterial walls, "site-specific" free radical production 15 could still proceed in their presence. In addition, activity of both SOD and GSH peroxidase or catalase may be necessary to prevent damaging free radical reactions since SOD produces hydrogen peroxide which can form hydroxyl radical in the presence of iron or ferrous proteins. ${ }^{33.34}$ Catalase or GSH peroxidase, if present, would prevent this reaction by catabolizing hydrogen peroxide.

Our results of measurement of SOD activity in blood-CSF mixtures incubated in vitro agree with those of Fujita et al. ${ }^{18.35}$ Kuwabara and colleagues, however, found SOD activity did not increase in supernatant fluid from blood-CSF mixtures incubated in vitro, a result they stated was due to rapid breakdown of SOD in supernatant fluid. ${ }^{36}$ Supernatant fluid becomes contaminated with large amounts of hemoglobin as erythrocytes lyse and SOD assays which rely on spectrophotometry in the visible spectrum may give unreliable results. ${ }^{9}$ We measured SOD activity by direct assay with potassium superoxide using ultraviolet spectrophotometry. Other investigators have reported increases in lipid peroxides in blood incubated in vitro. ${ }^{3}$ Activity of GSH peroxidase has not been measured in supernatant fluid from incubated flood-CSF mixtures.

This study shows that OxyHb-induced vasospasm is associated with lipid peroxidation products in CSF. Lipid peroxidation occurring in the absence of erythrocyte membranes suggests a mechanism of action of $\mathrm{OxyHb}$ could be direct free radicalmediated damage of arterial walls, leading to vasospasm and concomitant production of lipid peroxides.

\section{ACKNOWLEDGEMENTS}

We thank Arlene MacLean for preparing the manuscript, Sam Motyka and Karen Popowich for help with illustrations, and Ian Simpson for help with HPLC. Dr. Macdonald is a fellow of the Alberta Heritage Foundation for Medical Research. This work was supported in part by grants to Dr. Weir from the National Institutes of Health (5 R01 NS25946-03) and the Medical Research Council of Canada (MA 9158).

\section{REFERENCES}

1. Asano T, Tanishima T,. Sasaki T, Sano K. Possible participation of free radical reactions initiated by clot lysis in the pathogenesis of vasospasm after subarachnoid hemorrhage. In: Wilkins RH, ed. Cerebral Arterial Spasm. Baltimore, Williams and Wilkins 1980; 190-201.

2. Steele JA, Stockbridge N, Maljkovic G, Weir B. Free radicals mediate actions of oxyhemoglobin on cerebrovascular smooth muscle cells. Circ Res 1991; 68: 416-423.

3. Sasaki T, Asano T, Sano K. Cerebral vasospasm and free radical reactions. Neurol Med Chir (Tokyo) 1980; 20: 145-153.

4. Sasaki T, Wakai S, Asano T, Watanabe T, Kirino T, et al. The effect of a lipid hydroperoxide of arachidonic acid on the canine basilar artery. J Neurosurg 1981; 54: 357-365.

5. Macdonald RL, Weir BKA, Saito K, Kanamaru K, Findlay JM, et al. Etiology of cerebral vasospasm in primates. J Neurosurg 1991; 75: 415-424.

6. Elliott KAC, Jasper HH. Physiological salt solutions for brain surgery. J Neurosurg 1949; 6: 140-152.

7. Martin W, Villani GM, Jothianandan D, Furchgott RF. Blockade of endothelium-dependent and glyceryl trinitrate-induced relaxation of rabbit aorta by certain ferrous hemoproteins. J Pharmacol Exp Ther 1985; 233: 679-685.

8. Bull AW, Marnett LJ. Determination of malondialdehyde by ionpairing high-performance liquid chromatography. Analytical Biochem 1985; 149: 284-290.

9. Marklund SL. Direct assay with potassium superoxide. $I n$ : Greenwald RA, ed. CRC Handbook of Methods for Oxygen Radical Research. Boca Raton, CRC Press Inc., 1985; 249-255.

10. Wendel A. Glutathione peroxidase. In: Jakoby WB, ed. Methods in Enzymology. New York, Academic Press Inc. 1981; 77: 325333.

11. Gunzler WA, Kremers H, Flohe L. An improved coupled test procedure for glutathione peroxidase (EC 1.11.1.9) in blood. Z Klin Chem Klin Biochem 1974; 12: 444-448.

12. Liszczak TM, Varsos VG, Black P McL, Kistler JP, et al. Cerebral arterial constriction after experimental subarachnoid hemorrhage is associated with blood components within the arterial wall. J Neurosurg 1983; 58: 18-26.

13. Fujii S, Fujitsu K. Experimental vasospasm in cultured arterial smooth-muscle cells. Part I: contractile and ultrastructural changes caused by oxyhemoglobin. J Neurosurg 1988; 69: 9297.

14. Okada H, Endo S, Kamiyama K, Suzuki J. Oxyhemoglobininduced cerebral vasospasm and sequential changes of vascular ultrastructure. Neurol Med Chir (Tokyo) 1980; 20: 573-582.

15. Halliwell B, Gutteridge JMC. Oxygen free radicals and iron in relation to biology and medicine; some problems and concepts. Arch Biochem Biophys 1986; 246: 501-514.

16. Kanamaru K, Weir BKA, Findlay JM, Grace M, Macdonald RL. A dosage study of the effect of the 21 -aminosteroid U74006F on chronic cerebral vasospasm in a primate model. Neurosurgery 1990; 27: 29-38.

17. Steinke DE, Weir BKA, Findlay JM, Tanabe T, Grace M, et al. A trial of the 21 -aminosteroid $\mathrm{U} 74006 \mathrm{~F}$ in a primate model of chronic cerebral vasospasm. Neurosurgery $1989 ; 24: 179-186$.

18. Fujita Y, Shingu T, Gi H, Araki O, Matsunaga M, et al. Mechanism of cerebral vasospasm induced by oxyhemoglobin. $I n$ : Brock $\mathrm{M}$, ed. Modern Neurosurgery I. Berlin, Springer-Verlag, 1982; 359 374.

19. Misra HP, Fridovich I. The generation of superoxide radicals during the autoxidation of hemoglobin. J Biol Chem 1972;247: 6960-6962.

20. Wever R, Oudega B, Van Gelder BF. Generation of superoxide radicals during the autooxidation of mammalian oxyhemoglobin. Biochem Biophys Acta 1973; 302: 475-478.

21. Halliwell B, Gutteridge JMS, eds. Free Radicals in Biology and Medicine. Oxford, Clarendon Press 1985: 139-189. 
22. Koide T, Noda Y, Hata S, Sugioka K, Kobayashi S, et al. Contraction of the canine basilar artery following linoleic, arachidonic, 13-hydroperoxylinoleic, or 15-hydroperoxyarachidonic acid (41294). Proc Soc Exper Biol Med 1981; 168: 399-402.

23. Koide $T$, Neichi $T$, Takato $M$, Matsushita $H$, Sugioka $K$, et al. Possible mechanisms of 15-hydroperoxyarachidonic acidinduced contraction of the canine basilar artery in vitro. $\mathrm{J}$ Pharmacol Exp Ther 1982; 221: 481-488.

24. Suzuki N, Nakamura T, Imabayashi S, Ishikawa Y, Sasaki T, et al. Identification of 5-hydroxy eicosatetraenoic acid in cerebrospinal fluid after subarachnoid hemorrhage. J Neurochem 1983; 41: 1186-1189.

25. Sakaki S, Kuwabara H, Ohta S. Biological defence mechanism in the pathogenesis of prolonged cerebral vasospasm in the patients with ruptured intracranial aneurysms. Stroke 1986; 17: 196-202.

26. Watanabe T, Sasaki T, Asano T, Takakura K, Sano K, et al. Changes in glutathione peroxidase and lipid peroxides in cerebrospinal fluid and serum after subarachnoid hemorrhage - with special reference to the occurrence of cerebral vasospasm. Neurol Med Chir (Tokyo) 1988; 28: 645-649.

27. Sakaki S, Ohta S, Nakamura H, Takeda $S$. Free radical reaction and biological defense mechanism in the pathogenesis of prolonged vasospasm in experimental subarachoid hemorrhage. J Cereb Blood Flow Metab 1988; 8: 1-8.

28. Tokoro K. Cerebral vasospasm and lipoperoxide damage - morphological localization and measurement of lipoperoxide in prolonged cerebral vasospam. No Shinkei Geka 1984; 12: 1049-1058.
29. Feher J, Csomos G, Verecki A, eds. Free Radical Reactions in Medicine. Berlin, Springer-Verlag, 1987; 18-39.

30. Okamoto $\mathrm{S}$, Handa $\mathrm{H}$, Toda $\mathrm{N}$. Role of intrinsic arachidonate metabolites in the vascular action of erythrocyte breakdown products. Stroke 1984; 15: 60-64.

31. Toda N. Mechanisms of contracting action of oxyhemoglobin in isolated monkey and dog cerebral arteries. Am J Physiol 1990; 258: H57-H63.

32. Macdonald RL, Weir BKS, Runzer TD, Grace MGA, Poznansky MJ. Effect of intrathecal superoxide dismutase and catalase on oxyhemoglobin-induced vasospasm in monkeys. Neurosurgery 1992 (in press).

33. Halliwell B, Gutteridge JMC. Oxygen radicals and the nervous system. Trends Neurosci 1985; 8: 22-26.

34. Clemens MR, Einsele H, Remmer H, Waller HD. An essential requirement for ferrous-haemoglobin in the hydrogen peroxide stimulated oxidation of red blood cell membrane lipids. Biochem Pharmacol 1985; 34: 1339-1341.

35. Fujita Y, Shingu T, Yamada K, Araki O, Matsunaga M, et al. Noxious free radicals derived from oxyhemoglobin as a cause of prolonged vasospasm. Neurol Med Chir (Tokyo) 1980; 20: 137144.

36. Kuwabara H, Sakaki S, Nakano K, Yano M, Hatakeyama T, et al. A study on the changes of superoxide dismutase activity and the amount of lipid peroxide in patients with ruptured intracranial aneurysms with special reference to the pathogenesis of vasospasm. Nosochu no Geka 1982; 11: 159-164. 